\title{
Doubled haploids of interspecific hybrids between Brassica napus and Brassica rapa for canola production with valuable breeding traits
}

\author{
Ainash Daurova, Dias Daurov, Dmitriy Volkov, Kuanysh Zhapar, Daniyar Raimbek, Malika Shamekova \\ and Kabyl Zhambakin*
}

Laboratory of Breeding and Biotechnology, Institute of Plant Biology and Biotechnology, 45, Timiryazev str., 050040 Almaty, Kazakhstan

Received 12 March 2020 - Accepted 14 July 2020

\begin{abstract}
Doubled haploids (DH) were obtained from two interspecific hybrids between Brassica napus and Brassica rapa. Seeds of doubled haploid plants differed in colour and size. The hybridity of the obtained doubled haploid is shown using genomic in situ hybridization (GISH) analysis. Evaluation of drought tolerance during seed germination on PEG-6000 showed the advantage of doubled haploid plants of interspecific hybrids over the parent cultivars. The oil from seeds of doubled haploid plants showed good nutritional value.
\end{abstract}

Keywords: Brassica napus / Brassica rapa / interspecific hybrid / doubled haploid / drought tolerance

\begin{abstract}
Résumé - Haploïdes doublés d'hybrides interspécifiques entre Brassica napus et Brassica rapa pour la production de colza avec des caractéristiques de sélection avantageuses. Des haploïdes doublés (DH) ont été obtenus à partir d'hybrides interspécifiques entre Brassica napus et Brassica rapa. Les graines de ces plantes haploïdes doublés différaient en couleur et en taille. L'hybridité de l'haploïde doublé obtenu est démontrée par une analyse génomique par hybridation in situ (GISH). L'évaluation de la tolérance à la sécheresse pendant la germination des graines sur PEG-6000 a montré l'avantage des plantes doubles haploïdes issues d'hybrides interspécifiques par rapport aux cultivars parents. L'huile des graines de plantes doublement haploïdes a montré une bonne valeur nutritionnelle.
\end{abstract}

Mots clés : Brassica napus / Brassica rapa / hybride interspécifique / haploïde doublé / tolérance à la sécheresse

\section{Introduction}

The Climate of Kazakhstan is characterised by extreme volatility in meteorological conditions over the years and between seasons. At the same time, most of the farmland is located in high-risk environmental zones with low annual precipitation (150-320 $\mathrm{mm}$ ) and droughts of varying intensity (Feher and Fieldsend, 2019). The main regional areas of spring rapeseed cultivation are located in the north of the country where crops are mostly rainfed (USDA-FAS, 2010). Therefore, the main factor affecting spring rapeseed yield is drought. Since spring rainfalls are the major source of water for plants in northern Kazakhstan, it is important to grow crop varieties with a shorter vegetative season (USDA-FAS, 2010). At the same time, rapeseed varieties cultivated for the food industry,

*Correspondence: zhambakin@gmail.com known as "canola", need to have high-quality seed oil with a desired unsaturated fatty acid content (Kotlyarova et al., 2007). Creating interspecific rape hybrids with a yellow shell as well as low levels of erucic acid and glucosinolates may help resolve some of the aforementioned problems.

The Brassicaceae family is unique in its capability of interspecific hybridization, and many methods for such hybridization have already been discovered. This in turn facilitates the creation of synthetic complexes from different species as well as from their polyploids. Thus, effective model systems can be created to study the influence of polyploidy on crop yield (Lukens et al., 2006).

Interspecific hybridization of rapeseed can help to improve traits such as yield (Karim et al., 2014), resistance to pests and diseases (Neik et al., 2017) and the fatty acid composition of seed oil, increasing the contents of oleic and linoleic acids and reducing the erucic acid content (Iqbal et al., 2006). In addition, it facilitates the production of seeds with a yellow 
coat that have a technological advantage for oil extraction, in contrast to dark-coloured seeds (Matthew et al., 2009). While Brassica napus itself is an allopolyploid interspecific hybrids (Hu et al., 2019), only a limited number of interspecific and intergeneric crosses in the Brassicaceae family have resulted in full-value hybrid plants (Kotlyarova et al., 2007). Difficulties in creating interspecific hybrids are caused by incompatibility barriers that occur between different taxonomic groups at the time of pollination and occur all the way throughout the ontogenesis of hybrid plants (Karim et al., 2014).

However, various combinations of interspecific hybrids can be quickly transferred into a homozygous state through an isolated microspore culture. This technology has been successfully introduced and widely implemented, particularly for the Brassicaceae family. It has successfully been applied for obtaining haploids and doubled haploids of species such as B. napus (Zhou et al., 2002; Weber et al., 2005), Brassica oleracea (Phippen, 1990), Brassica carinata (Barro et al., 2001; Barro et al., 2003), Brassica juncea (Lionneton et al., 2001) and Brassica rapa (Gu et al., 2003; Ferrie and Keller, 2005).

Haploid technology plays an important role in plant breeding. It allows to quickly identify the optimal gene combinations and reduce the time for creating new cultivars. Doubled haploids of more than 300 species have been reported (Wedzony et al., 2009; Germana, 2011). Doubled haploids obtained in vitro can be applied not only in practical breeding, but also in genetic engineering and in cellular plant breeding. The advantage of producing doubled haploids in an isolated microspore culture is the rapid production of homozygous material, which can be immediately assessed for its suitability for use in breeding process. Thus, subsequent seed reproduction should not result in any deviation from quantitative and qualitative characteristics in the following generations (Snowdon et al., 1997; Wen et al., 2012). As a result of using this technology, we can get new genotypes that will allow breeders to quickly select the desired genotypes due to the homozygosity of doubled haploids.

The strategy for production hybrid can be greatly simplified by evaluating the offspring using cytological methods.

Genomic in situ hybridization (GISH) is a reliable method for identifying parental genetic material in hybrid genomes at the chromosomal level. An important advantage of GISH over other molecular-genetic methods for analysing hybrids is that GISH does not require prior knowledge of nucleotide composition of the genome and allows coverage of the entire genome (Snowdon et al., 1997). It has therefore successfully been applied to identify parental chromosomes and to monitor the introgression of genetic material from donor to recipient in potatoes (Gavrilenko et al., 2001), triticale (Aliyeva et al., 2015), rapeseed (Snowdon et al., 1997) and other cultures. The method is based on the visualisation of DNA sequences in chromosomes that differ between parents. Using labelled genomic DNA of one parent and unlabelled genomic DNA of the second parent, one can get a fluorescent signal that allows the differentiation between parental chromosomes in an interspecific hybrid by blocking homologous sequences (Marasek et al., 2004). However, it is difficult to detect intergenomic rearrangements in Brassica chromosomes. Also, due to a concentration of heterochromatin around the centromeric regions, and the extensive intergenomic homoeology among the Brassicaceae, genomic probes often do not hybridize uniformly across the entire length of the chromosomes (Snowdon et al., 1997).

A more precise determination of chromosomal rearrangements can be performed using the combined fluorescent/ genomic in situ hybridization (FISH/GISH) method (Abbasi et al., 1999; Cao et al., 2000). It can be applied in hybridization with the whole genomic DNA as a probe to distinguish genomes as well as with chromosome-specific DNA probes to either identify mitotic chromosome pairs or to visualise the pairing of homologous chromosomes in meiosis (Maluszynska and Hasterok, 2005; Weerakoon, 2011). In addition, the GISH method allows the chromosomes of genomes A and B in B. juncea to be distinctly labelled (Weerakoon et al., 2009). Multicolour FISH with an rDNA probe in combination with GISH helped to identify 28 chromosomes of these species (Maluszynska and Hasterok, 2005).

One of the limiting stress factors for cultivating canola is drought. This environmental condition significantly affects yield at the flowering stage (Xie et al., 2013) and seriously influences the fatty acid composition of seeds, particularly oleic and erucic acid contents (Yuan et al., 2015).

In comparison to $B$. napus, $B$. rapa may harbour a superior and more rapid response to drought stress (Guo et al., 2017). Accordingly, hybrids between these species may be more drought-tolerant than rapeseed B. napus. For determine tolerance to drought, experiments are carried out method of simulating drought using a hypertonic solution of polyethylene glycol (PEG-6000). Using of PEG is one of the appropriate procedures to create drought conditions for screening some parameters of drought tolerance, such as germination, plant height, root length, relative water content (RWC) (Basha et al., 2015). Some authors confirm that simulating drought using PEG in plants consists in influencing the lipid composition of membranes, which is a key component in photosynthesis (Wang et al., 2020), and also leads to some changes in the structure of chloroplasts (Khan et al., 2019). Using PEG-6000 to simulate drought is a very simple and fast method for early detection of drought tolerance (Xie et al., 2013).

Therefore, the main aim of this work is to produce doubled haploids of hybrids between $B$. napus and $B$. rapa. The resulting doubled haploids (a) determine the degree of their hybridity using GISH analysis; (b) determine their prospects for resistance to drought using PEG-6000; (c) determine their fatty acid composition according to the technical parameters necessary for canola.

\section{Materials and methods}

We used previously obtained (Zhambakin et al., 2017) hybrid seeds of two combinations: Kris $($ B. napus $) \times$ Zolotistaya $(B$. rapa) $(\mathrm{BKZ})$ and $\mathrm{Kris}(B$. napus $) \times$ Yantarnaya (B.rapa) (BKY). To obtain hybrid seeds, we used one cultivar of rapeseed $B$. napus (Kris-All-Russia Research Institute of Agricultural Biotechnology, Moscow, Russia) and two cultivars of rape (B. rapa ("Zolotistaya" and L. "Yantarnaya") - Federal state budgetary scientific institution "Federal scientific center" "V.S. Pustovoit All-Russian Research Institute of Oil crops"). 


\subsection{Isolation of a microspore culture}

Buds ( $2-3 \mathrm{~mm}$ in size) were collected in field conditions early in the morning at the single-nucleus microspore stage during hours of intense pollen division. The pretreatment of buds was carried out in a $10 \mathrm{mg} / \mathrm{l}$ silver nitrate solution at $+4{ }^{\circ} \mathrm{C}$ for 2 days. Subsequently, the buds were sterilised with $5 \%$ sodium hypochlorite for $7-10 \mathrm{~min}$ and $70 \%$ alcohol for $3-5 \mathrm{~s}$, followed by three washes with distilled water. The buds were then placed in a cool micromixer $\left(10^{\circ} \mathrm{C}\right)$ using $30-40 \mathrm{ml}$ of cooled B5 medium (Gamborg and Eveleigh, 1968) without hormones $\left(10-12^{\circ} \mathrm{C}\right)$ and homogenised for $7-9 \mathrm{~s}$ at high speed. The resulting suspension was passed through a filter $(80 \mu \mathrm{m})$, and the filtrate was centrifuged (Eppendorf, Germany) at $100 \mathrm{~g}$ for $5 \mathrm{~min}$. The supernatant was decanted, and $15 \mathrm{ml}$ of the B 5 medium were added to the precipitate, followed by centrifugation for $5 \mathrm{~min}$. After repeating the previous step, the precipitate was poured into Petri dishes. Subsequently, NLN medium with $0.05 \mathrm{mg} / \mathrm{l}$ benzylaminopurine (BA) was added for microspore cultivation. The concentration of microspores in the NLN medium was adjusted to $35000-50000$ microspores per $\mathrm{ml}$. Petri dishes were placed in a temperature controller with a shaker at $25^{\circ} \mathrm{C}$. As soon as torpedo-like embryoids appeared, the Petri dishes were exposed to light at the same temperature (Swanson, 1990).

Embryoids derived from the isolated microspore culture were transplanted onto Gamborg B5 solid nutrient medium supplemented with $1 \mathrm{mg} / \mathrm{l}$ gibberellic acid. As regeneration proceeded, the plants were transplanted onto MurashigeSkoog hormone-free medium with half salt composition, one plant per tube, and placed into a room with controlled light and temperature.

\subsection{Colchicine}

Regenerated plants were cloned in vitro. The clones were then germinated to the stage of five leaves and treated with $0.05 \%$ colchicine. After that, treated plants were washed three times with distilled water, transferred to soil and grown until the formation of seeds in doubled haploid plants of interspecific hybrid combinations (Gland, 1981).

\subsection{GISH analysis: preparation of microscope slides}

To obtain mitotic metaphase plates, the seeds of hybrids were germinated on moist filter paper in Petri dishes for 2 days. Subsequently $1.5-2-\mathrm{cm}$ long roots were pretreated in $2 \mathrm{mM}$ 8-ortho-oxyquinoline for $4 \mathrm{~h}$ at $25^{\circ} \mathrm{C}$ and fixed in an ethanol + acetic acid solution at a ratio of $3: 1$. Fixed roots were washed in citrate buffer $(0.01 \mathrm{M}$ citric acid $+0.01 \mathrm{M}$ sodium citrate, $\mathrm{pH}$ 4.8 ) and treated with an enzymatic mixture of $1 \%$ cellulase (Sigma Aldrich, USA) and 2\% pectinase (Sigma Aldrich, USA) for $1.5-2 \mathrm{~h}$ at $37^{\circ} \mathrm{C}$. After separation from the non-meristematic parts, root tips were squashed in a drop of $45 \%$ acetic acid and the preparations were frozen (Hasterok et al., 2005).

\subsection{DNA labelling and GISH}

DNA labelling and GISH were performed according to a method described previously (Hasterok et al., 2005). The DNA of seed parents was labelled with digoxigenin-11-dUTP (Roche, Mannheim, Germany) (B. rapa) and rhodaminedUTP (Roche, Mannheim, Germany) (B. napus) fluorochrome labels using the nick-translation (Sigma Aldrich, St. Louis, MI, USA) method. The samples were pretreated with RNase (without DNase, $100 \mu \mathrm{g} / \mathrm{ml}, 1 \mathrm{~h}$ at $37^{\circ} \mathrm{C}$ ) and washed three times in $2 \times \mathrm{SSC}$ buffer (saline-sodium citrate $\mathrm{NaCl}+$ $\mathrm{Na}_{3}-\mathrm{C}_{6} \mathrm{H}_{5} \mathrm{O}_{7} \times 5.5 \mathrm{H}_{2} \mathrm{O}+\mathrm{H}_{2} \mathrm{O}$ ). Post-fixation was performed in a $4 \%$ aqueous formaldehyde solution. The hybridization mixture consisted of $50 \%$ deionized formamide, $10 \%$ dextran sulphate, $2 \times \mathrm{SSC}, 0.5 \% \mathrm{SDS}$ and the DNA probe. The hybridization mixture was preliminarily denatured at $75^{\circ} \mathrm{C}$ for $10 \mathrm{~min}$ and then applied to the slides. The samples and the hybridization mixture were denatured together at $75^{\circ} \mathrm{C}$ for $5 \mathrm{~min}$ and left to hybridize overnight in a humid chamber at $37^{\circ} \mathrm{C}$. After stringent washing $(20 \%$ formamide in $0.1 \times \mathrm{SSC}$ at $42^{\circ} \mathrm{C}, 2 \times 5$ ), immunodetection was performed with FITCconjugated anti-digoxigenin (Roche, Mannheim, Germany). Final samples contained $2 \mu \mathrm{g} / \mathrm{ml}$ DAPI in Vectashield antifade mounting medium (Vector Laboratories, Burlingame, CA, USA).

\subsection{Determining the drought tolerance using polyethylene glycol 6000 (PEG-6000).}

Hybrid seeds were presoaked in water for $24 \mathrm{~h}$. Subsequently, the seeds were sterilised in sodium hypochlorite for $10 \mathrm{~min}$, then in $70 \%$ ethanol for $3-5 \mathrm{~s}$, and finally thoroughly washed with sterile water three to four times. After sterilisation, the seeds were sown in Petri dishes (10 pieces per dish) with PEG-6000-impregnated filter paper and incubated at $25^{\circ} \mathrm{C}$ in a $16 \mathrm{~h} / 8 \mathrm{~h}$ day/night photoperiod. Observations were carried out daily. Hypocotyl and root growth indicators were recorded over 8 days (Xie et al., 2013).

\subsection{Evaluation of the fatty acid composition}

Samples for chromatography were prepared as follows: $0.5 \mathrm{ml}$ of seed oil ( 10 seeds that were produced under the same environmental conditions) was extracted in a mill. Then, $8 \mu \mathrm{l}$ of the oil were collected with a pipette into a glass tube. There after that, $2 \mathrm{ml}$ of hexane and $0.1 \mathrm{ml}$ of $5 \%$ sodium methylate were added to the oil. The tube was left to sit for $30 \mathrm{~min}$ with periodical shaking at least three times. After the incubation period $1 \mathrm{ml}$ of distilled water was added to the tube, and the tube was then shaken and allowed to settle. Subsequently, $1 \mathrm{ml}$ of the upper hexane layer was transferred to a penicillin vial, which was placed under a fan at room temperature until the hexane was completely evaporated. After drying, $600 \mu \mathrm{l}$ of chemically pure hexane were added to the vial. The fatty acid composition was determined by gas chromatography (GOST R, 1999).

\subsection{Statistical analysis}

Significant results were tested using Analysis of Variance (ANOVA) by applying the Fisher LSD test with with the program SPSS 22 (IBM). Means with different letters are regarded as statistically significant at $p<0.05$. 


\section{Results}

\subsection{Obtaining doubled haploid seeds of interspecific hybrids}

The previously obtained seeds (F1) of hybrid combinations BKZ and BKY were sown on the experimental field. Cultivated hybrid plants (F1) were used to produce doubled haploids of interspecific hybrids by isolated microspore culture.

Figure 1 illustrates the developmental stages from an isolated microspore through numerous divisions to the production of a bipolar embryo and its derived regenerated plants. In total, 152 to 162 embryos per 100 buds were derived using an isolated microspore culture from two hybrid combinations: BKZ, BKY. Depending on the hybrid combination, the percentage of regenerants derived from embryos varied between 38.8 and $43 \%$ (Tab. 1).

In this experiment, only part of the embryos from each combination was used to obtain haploid plants, and only some of them were treated with colchicine. Another part of them was cloned for other experiments. Most colchicine-treated plants were sterile (Tab. 1).

The resulting doubled haploids of interspecific hybrids seeds differed phenotypically from the parents $B$. napus and B. rapa cultivars. The DHBKY hybrid combination produced yellow-brown seeds, while the seeds of the DHBKZ hybrid were brown (Fig. 2). The seeds of the DHBKZ combination hybrid were small, similar to B. napus seeds. At the same time, the weight of 1000 seeds of cultivar Kris was $3 \mathrm{~g}$, and in doubled haploids of interspecific hybrids plants, it varied from 1.1 to $4 \mathrm{~g}$.

Thus, seeds of doubled haploids of interspecific hybrids were obtained, which differed in colour, size, as well as in quantitative traits, the weight of 1000 seeds. Further, the obtained hybrid seeds of doubled haploids were used to (a) determine the hybridity using GISH analysis; to (b) assess resistance to drought in laboratory conditions; to (c) quantifity their fatty acid composition.

\subsection{GISH analysis}

In our case, we wanted to show the hybridity of doubled haploids obtained in the culture of isolated microspores B. napus $\times$ B. rapa. Figure 3 shows a GISH analysis of the obtained seeds of doubled haploids of interspecific hybrids of DHBKZ, which were stained with DAPI and contained chromosomes from the genome of the donor plant. Fluorescent signals are clearly present on each chromosome of the hybrid. The predominant localization of hybridization signals was observed in the centromeric region. In seven doubled haploids of interspecific hybrids chromosomes, hybridization signals were much stronger in the centromere regions of the chromosomes, while the telomere signals were weak. The GISH analysis clearly showed the presence of $B$. rapa DNA in seven chromosomes of $B$. napus $\times$ B. rapa hybrid combination. It is likely that the yellow colour of the seeds was transmitted to B. napus from the chromosomes of B. rapa genome A.
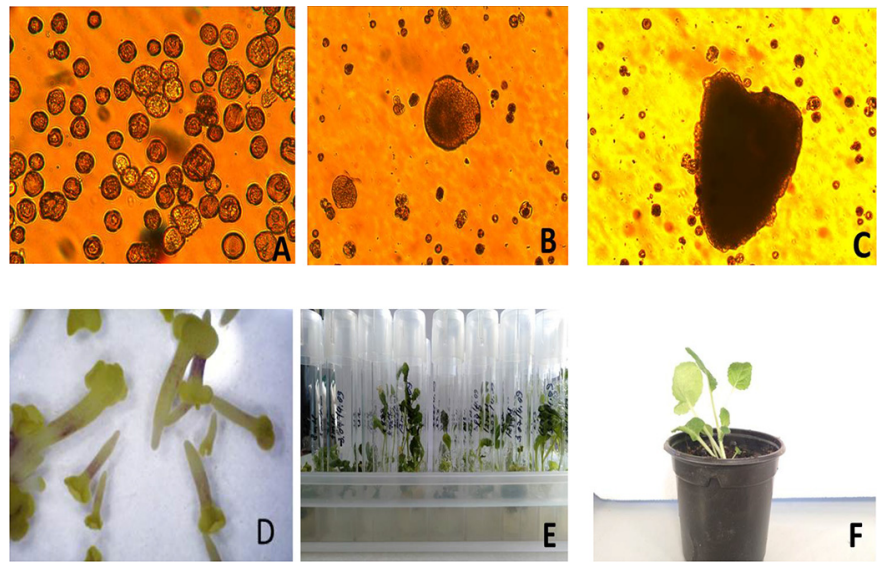

Fig. 1. Embryogenesis of microspores of interspecies hybrids of B. napus $\times$ B. rapa. (A) Microspores that had been cultivated for one week. (B, C) Globular- and torpedo-shaped embryos. (D) Microspore-derived embryos (MDE). (E, F) Regenerated plantlets from embryos. Bar $=100 \mu \mathrm{m}$.

\subsection{Drought tolerance test}

Figure 4 shows the results of drought-tolerance tests of doubled haploids of interspecific hybrids and their parents. The doubled haploids of interspecific hybrids differed from the parents in the percentage of seed germination and relative water content in seedlings. Seed germination of all varieties of parents and doubled haploid of interspecific hybrids in the control group ( $0 \% \mathrm{PEG})$ began after $24 \mathrm{~h}$ and reached $100 \%$. With the increase in the concentration of PEG-6000, the rate of seed germination of $B$. napus significantly decreased.

The seed germination rate of $B$. napus cultivars (female parents) at $20 \%$ of PEG-6000 made up only 33\%, while B. rapa cultivars showed much higher rates: "Yantarnaya" B. rapa obtained $66 \%$, while "Zolotistaya" reached $93 \%$. Compared with the parent seeds, seeds of doubled haploids of interspecific hybrids showed average results around $60 \%$.

The relative water content in $B$. rapa seedlings was higher than that in $B$. napus. The highest percentage of water content was registered for seedlings of $B$. rapa L. "Yantarnaya", which made up $62 \%$, followed by B. rapa L. "Zolotistaya" (56.5\%) at $20 \%$ of PEG- 6000 . The water content in seedlings of the B. napus cultivar ("Kris") was about $46 \%$.

The amount of water in seedlings of doubled haploids of interspecific hybrids was higher than that in parental seedlings. The relative water content in the seedlings was $75.4 \%$ for hybrids of DHBKZ and 70\% for hybrids of DHBKY.

\subsection{Fatty acid composition of doubled haploid seeds of interspecific hybrids}

Table 2 presents the results of doubled haploids of interspecific hybrid fatty acid composition analysis. Erucic acid was not detected in any seed. In terms of oleic acid content, the DHBKY doubled haploid of interspecific hybrids had the highest percentage of oleic acid (68.94\%). At the same time, the amount of saturated fatty acids of interspecific hybrids remained relatively low compared to $B$. napus and $B$. rapa. 
Table 1. Embryogenesis, regeneration, and seed production of doubled haploids of F1 interspecific hybrids of $B$. napus $\times$ B. rapa.

\begin{tabular}{|c|c|c|c|c|c|}
\hline \multirow[t]{2}{*}{$\begin{array}{l}\text { Name of hybrid } \\
\text { combination }\end{array}$} & \multirow[t]{2}{*}{$\begin{array}{l}\text { Number of formed } \\
\text { embryos } / 100 \text { buds }\end{array}$} & \multicolumn{2}{|c|}{$\begin{array}{l}\text { Number of plants } \\
\text { from embryos }\end{array}$} & \multirow[t]{2}{*}{$\begin{array}{l}\text { Number of plants } \\
\text { treated with colchicine }\end{array}$} & \multirow[t]{2}{*}{$\begin{array}{l}\text { Number of fertile plants } \\
\text { from embryos } n / \%\end{array}$} \\
\hline & & $n$ & $\%$ & & \\
\hline F1 BKY & 162 & 139 & 31 & 72 & $28 / 38.8$ \\
\hline
\end{tabular}

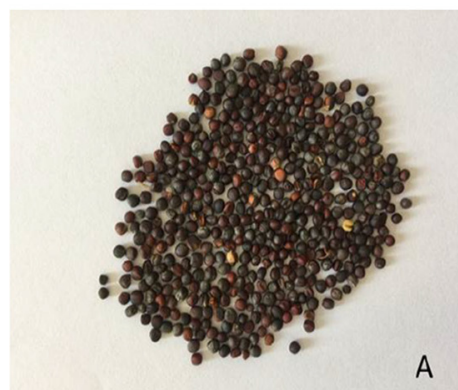

A

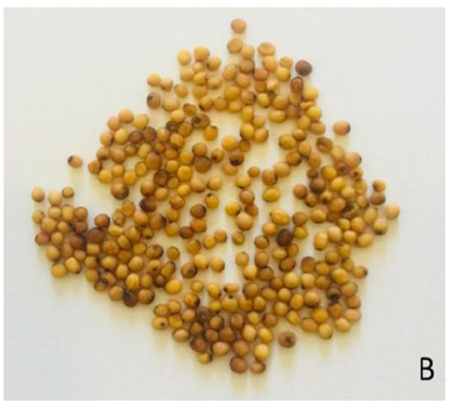

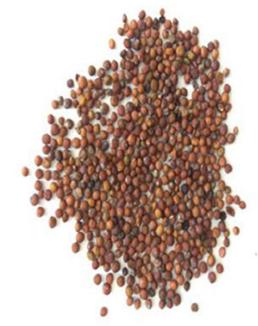

C

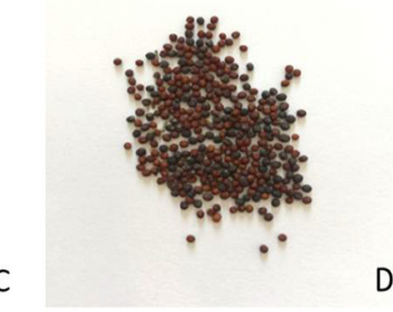

Fig. 2. Seeds of doubled haploids of interspecific hybrids B. napus $\times$ B. rapa. (A) Seeds of B. napus. (B) Seeds of B. rapa. (C) Yellow-brown seeds of the hybrid DHBKY. (D) Small brown seeds of the hybrid DHBKZ.
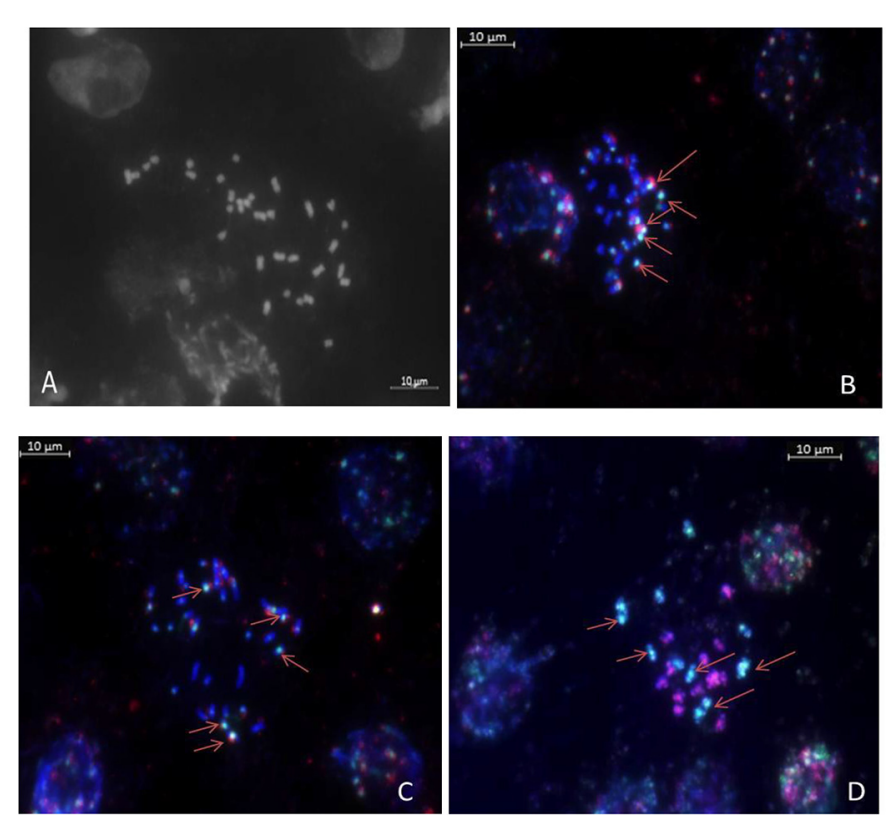

Fig. 3. Genomic in situ chromosome hybridization of DHBKZ. In all images, chromosomes are stained with DAPI (blue) and probed for the genomic DNA of $B$. napus, fluorescently labelled with rhodamine5-dUTP (red), and the genomic DNA of B. rapa labelled with digoxigenin-11-dUTP (green). (A) Chromosomes of hybrids under light microscope, 2n-33 chromosomes. (B, C, D) GISH analysis of interspecific hybrid of $B$. napus x $B$. rapa (arrows indicate chromosomes transmitted from $B$. napus).

\section{Discussion}

Interspecific hybrids of the Brassicaceae family are excellent material for producing doubled haploids using an isolated microspore culture (Zhou and Scarth, 1995). As a result due to the allopolyploid nature of B.napus, a completely new homozygous and, at the same time, hybrid plant may appear, having the most diverse combination of chromosomes of Brassica species (Li et al., 2018). In our experiment, we obtained a rather high embryogenesis productivity in a culture of isolated microspores and a rather high level of plant regeneration. As a result of colchicine treatment, more than a third of the plants were fertile. Among the obtained hybrids, plants with an intermediate seed colour from dark yellow to brown were noted.

In the present work, GISH analysis was used to confirm the hybrid nature of doubled haploids of interspecific hybrids of B. napus and B. rapa. This method has been successfully applied to identify parental chromosomes in hybrids with small chromosomes in B. napus breeding (Hasterok et al., 2005). The GISH method, performed on doubled haploids of interspecific hybrids of $B$. napus and B. rapa, allowed us to clearly identify the chromosomes of the parental species in the nucleus of doubled haploids of interspecific hybrids. In the metaphase of doubled haploids of interspecific hybrids, GISH analysis showed the origin of conjugation of chromosome regions. But our results using GISH hardly resemble the typical "chromosome painting" image of hybridization with the total genomic DNA probe. Despite this, as shown in Figure 2, the GISH method was effectively applied for the detection of parental genomes in Brassica hybrids. A lack of moisture is a major deterrent to the cultivation of rapeseed in Kazakhstan. Therefore, selection for the cultivation of drought-tolerant varieties and hybrids of rapeseed (canola) is an urgent problem. Channaoui et al. (2019) carried out work on the assessment of drought resistance and the use of PEG-6000 of the Brassica family. Similarly, researchers from China (Yang et al., 2007) tested for drought-resistance using PEG-6000 on 14 varieties of rapeseed.

In our experiment, we indirectly evaluted the resistance to drought of plants of the doubled haploids of interspecific 

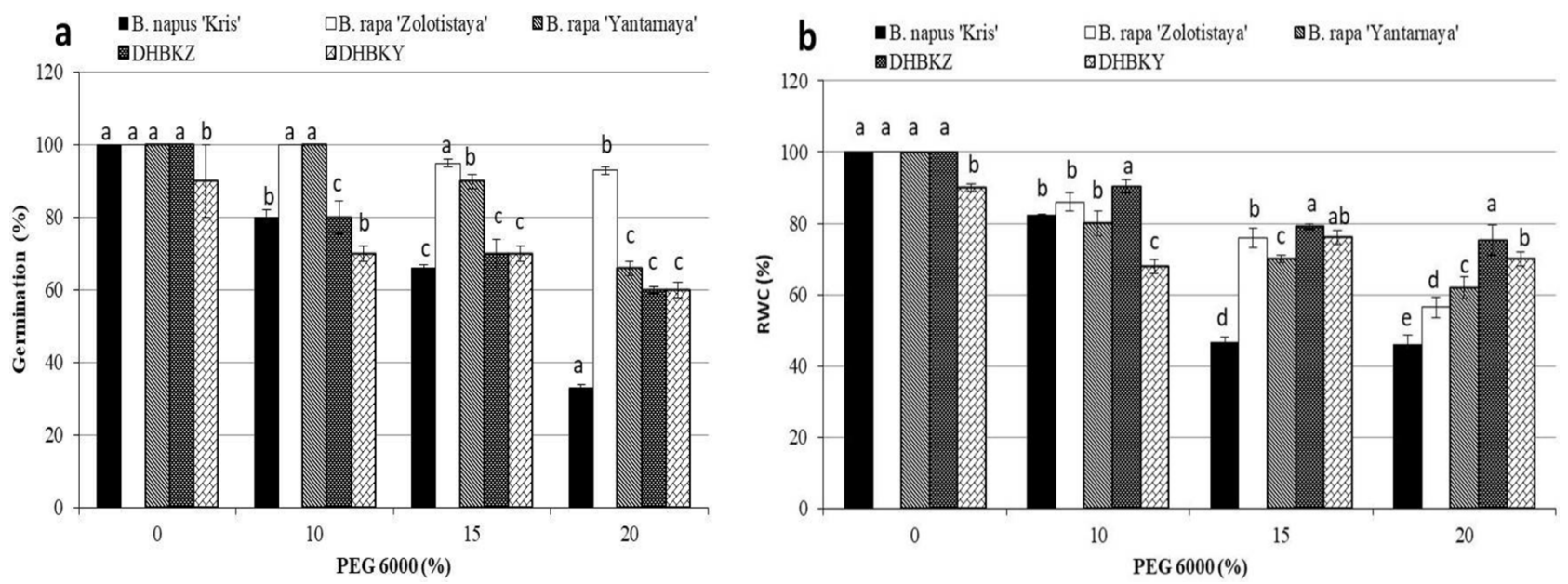

Fig. 4. Effect of PEG-6000 induced water stress on seed Germination (a) and on Relative Water Content (RWC); (b) of controls (B. napus, B. rapa) and hybrids seedlings (DHBKZ, DHBKY). Data are means \pm SD bars of three experiments $(n=20$ seeds per experiment), measured in triplicate. The same letter indicates no significant difference and the different letters indicate a significant difference (Fisher's LSD, $P<0.05)$.

Table 2. Fatty acid composition of the seed oil of the parents and doubled haploids of interspecific B. napus hybrids.

\begin{tabular}{|c|c|c|c|c|c|c|c|c|}
\hline \multirow[b]{2}{*}{ Nam } & \multicolumn{8}{|c|}{ Fatty acid concentration, $\%$} \\
\hline & & $\mathrm{P}$ & $\mathrm{S}$ & $\mathrm{O}$ & $\mathrm{L}$ & $\mathrm{Ln}$ & B & $\mathrm{Er}$ \\
\hline \multirow{3}{*}{ Parents (Control) } & B. napus "Kris" & 4.5 & 2.1 & 61.9 & 19.5 & 6.2 & 0.4 & $<0.05$ \\
\hline & B. rapa "Zolotistaya" & 5.7 & 1.6 & 51.7 & 28.1 & 7.3 & 0.1 & $<0.05$ \\
\hline & B. rapa "Yantarnaya" & 4.7 & 1.8 & 53.8 & 24.9 & 6.8 & 0.2 & $<0.05$ \\
\hline \multirow{2}{*}{ Doubled haploid hybrids } & DHBKZ & 3.6 & 2.1 & 67.8 & 18.1 & 5.7 & 0.2 & $<0.05$ \\
\hline & DHBKY & 3.9 & 2.9 & 68.9 & 18.3 & 2.2 & 0.2 & $<0.05$ \\
\hline
\end{tabular}

P: palmitic acid; S: stearic acid; O: oleic acid; L: linoleic acid; Ln: linolenic acid; Er: erucic acid; B: behenic acid.

hybrids in comparison with plants of $B$. napus and $B$. rapa by the percentage of seeds germinated in an osmotic solution of various concentrations. The physiological basis of this method is the ability of plant seeds to germinate in PEG-6000 solution. A high percentage of sprouted seeds reflects the ability of the genotype to use scarce soil moisture reserves, which indicates its resistance to drought in the initial stages of development. Assessment of drought resistance during seed germination on PEG-6000 in our experiment showed the advantage of a doubled haploid of interspecific hybrids over the varieties of parents $B$. napus and B. rapa.

Rapeseed is grown in Kazakhstan for the production of edible oil (canola) both for domestic consumption and for export. The quality of canola oil is determined mainly by the high contents of unsaturated (oleic, linoleic, linolenic) and low saturated (palmitic and stearic) fatty acids; in addition, the content of erucic acid should not exceed $2 \%$. At the same time, the requirements for oil quality are increasing constantly. In particular, vegetable oils with a high content of oleic acid are relevant for a healthy diet (Bowen et al., 2019). The fatty acid composition of the doubled haploid seeds obtained by us fully meets the modern requirements for canola cultivars.
In our work, the obtained doubled haploid plants were characterised by resistance to arid growing conditions, and the seed quality met the technological requirements for canola. Further work should aim at testing the doubled haploids of interspecific hybrids in the field conditions of northern Kazakhstan to create new canola cultivars (000).

\section{Abbreviations}

BA

GISH

PEG
Benzylaminopurin

Genomic in situ hybridization Polyethylene glycol

\section{Funding acknowledgement statement}

The work was carried out with grant funding support for the project AP05130871 "Creating doubled haploid mutant lines of $B$. napus, B. rapa and their hybrids using in vitro mutagenesis to obtain high-quality oil with high oleic acid content" from the Science Committee of the Ministry of Education and Science of the Republic of Kazakhstan. 
Acknowledgement. The authors of the article express their gratitude to Professor R. Hasterok from Silesian University for his support during GISH analysis.

\section{References}

Abbasi FM, Brar DS, Carpena AL, Fukui K, Khush GS. 1999. Detection of autosyndetic and allosyndetic pairing among A and E genomes of Oryza through genomic in situ hybridization. Rice Genet Newsl 16: 24-25.

Aliyeva AJ, Mehdiyeva SP, Kerimova RK. 2015. Raise of shortstemmed vaviloid branched spike lines and their cytogenetics. Vavilov J Genet Breed 19(1): 91-96.

Barro F, Fernandez-Escobar J, De la Vega M, Martin A. 2001. Doubled haploid lines of Brassica carinata with modified erucic acid content through mutagenesis by EMS treatment of isolated microspores. Plant Breed 120: 262-264.

Barro F, Fernandez-Escobar J, De la Vega M, Martin A. 2003. Modification of glucosinolate and erucic acid contents in doubled haploid lines of Brassica carinata by UV treatment of isolated microspores. Euphytica 129: 1-6.

Basha P, Sudarsanam G, Madhu Sudhana Reddy M, Siva Sankar N. 2015. Effect of PEG induced water stress on germination and seedling Development of tomato germplasm. Int J Recent Sci Res 6(5): 4044-4049.

Bowen KJ, Kris-Etherton PM, West SG, et al. 2019. Diets enriched with conventional or high-oleic acid canola oils lower atherogenic lipids and lipoproteins compared to a diet with a western fatty acid profile in adults with central adiposity. $J$ Nutr 149(3): 471-478.

Cao M, Sleper DA, Dong F, Jiang J. 2000. Genomic in situ hybridization (GISH) reveals high chromosome pairing affinity between Lolium perenne and Festuca mairei. Genome 43: 398403.

Channaoui SE, Idrissi IS, Mazouz H, Nabloussi A. 2019. Reaction of some rapeseed (Brassica napus L.) genotypes to different drought stress levels during germination and seedling growth stages. $O C L$ 26: 23.

Feher I, Fieldsend AF. 2019. The potential for expanding wheat production in Kazakhstan. Analysis from a food security perspective. JRC Tech Rep 2019: 111.

Ferrie AMR, Keller WA. Development of methodology and applications of doubled haploids in Brassica rapa. In: GCIRC Proceedings of the Ninth International Rapeseed Congress, GCIRC, Cambridge, UK, 1995, pp. 805-809.

Gamborg OL, Eveleigh D. 1968. Culture methods and detection of glucanases in suspension cultures of wheat and barley. Can J Biochem Physiol 46: 417-421.

Gavrilenko T, Thieme R, Rokka VM. 2001. Cytogenetic analysis of Lycopersicon esculentum (+) Solanum etuberosum somatic hybrids and their androgenic regenerants. Theor Appl Genet 103: 231-239.

Germana MA. 2011. Anther culture for haploid and doubled haploid production. Plant Cell Tissue Org Cult 104: 283-300.

Gland A. 1981. Doubling chromosomes in interspecific hybrids by colchicine treatment. Eucarpia Cruciferae Newsl 6: 20-22.

GOST R 51483-99. 1999. Vegetable oils and animal fats. Determination by gas chromatography of constituent contents of methyl esters of total fatty acid content, pp. 151-159.

Gu H, Zhu J, Zhang G, Zhou W. 2003. Microspore culture and ploidy identification of regenerated plant in Chinese flowering cabbage (Brassica rapa ssp. parachinensis). J Agric Biotechnol 11(6): 572-576.
Guo YM, Samans B, Chen S, et al. 2017. Drought-tolerant Brassica rapa shows rapid expression of gene networks for general stress responses and programmed cell death under simulated drought stress. Plant Mol Biol Rep 35:416-430.

Hasterok R, Ksiazczyk T, Wolny E, Maluszynska J. 2005. FISH and GISH analysis of brassica genomes. Acta Biol Cracoviensia Ser Bot 47(1): 185-192.

Hu D, Zhang W, Zhang Y, et al. 2019. Reconstituting the genome of a young allopolyploid crop, Brassica napus, with its related species. Plant Biotechnol J 17: 1106-1118. http://dx.doi.org/10.1111/ pbi.13041.

Iqbal MCM, Weerakoon SR, Peiris PKD. 2006. Variability of fatty acid composition in interspecific hybrids of mustard Brassica juncea and Brassica napus. Ceylon J Sci (Biol Sci) 35(1): 17-23.

Karim MM, Siddika A, Tonu NN, et al. 2014. Production of high yield short duration Brassica napus by interspecific hybridization between B. oleracea and B. rapa. Breed Sci 63: 495-502.

Khan MN, Zhang J, Luo T, et al. 2019. Seed priming with melatonin coping drought stress in rapeseed by regulating reactive oxygen species detoxification: Antioxidant defense system, osmotic adjustment, stomatal traits and chloroplast ultrastructure perseveration. Ind Crops Prod 140: 111597. http://dx.doi.org/10.1016/j. indcrop.2019.111597.

Kotlyarova EB, Zhidkova EN, Podvigina OA. 2007. Application of in vitro methods for obtaining remote and intergeneric hybrids of plants of the Brassicaceae family. Proc VSU, Ser: Chem Biol Pharm 2: 64-70.

Li Q, Chen Y, Yue F, Qian W, Song H. 2018. Microspore culture reveals high fitness of $B$. napus-like gametes in an interspecific hybrid between Brassica napus and B. oleracea. PLoS ONE 13 (3): e0193548

Lionneton E, Beuret W, Delaitre CO, Chatt S, Rancillac M. 2001. Improved microspore culture and doubled-haploid plant regeneration in the brown condiment mustard (Brassica juncea). Plant Cell Rep 20: 126-130.

Lukens LN, Pires JC, Leon E, Vogelzang R, Oslach L, Osborn T. 2006. Patterns of sequence loss and cytosine methylation within a population of newly resynthesized Brassica napus allopolyploids. Plant Physiol 140: 336-348.

Maluszynska J, Hasterok R. 2005. Identification of individual chromosomes and parental genomes in Brassica juncea using GISH and FISH. Cytogenetic Genome Res 109: 310-314.

Marasek A, Hasterok R, Wiejacha K, Orlikowska T. 2004. Determination by GISH and FISH of hybrid status in Lilium. Hereditas 140: 1-7.

Matthew NN, Annaliese ASM, Marie-Claire C, Linda Th, Guijun Y, Wallace AC. 2009. Microspore culture preferentially selects unreduced (2n) gametes from an interspecific hybrid of Brassica napus L. $\times$ Brassica carinata Braun. Theor Appl Genet 119: 497505.

Neik TX, Barbetti MJ, Batley J. 2017. Current status and challenges in identifying disease resistance genes in Brassica napus. Front Plant Sci 8: 1788

Phippen C. 1990. Genotype plant bud size and media factors affecting anther culture of cauliflowers (Brassica oleracea var botrytis). Theor Appl Genet 79: 33-38.

Snowdon RJ, Kohler W, Friedt W, Kohler A. 1997. Genomic in situ hybridization in Brassica amphidiploids and interspecific hybrids. Theor Appl Genet 95: 1320-1324.

Swanson EB. 1990. Microspore culture in brassica. Methods Mol Biol 6: 159-169.

USDA-FAS. 2010. Kazakhstan agricultural overview. Commodity Intelligence Report of United. 
Wang Y, Zhang X, Huang G, et al. 2020. Dynamic changes in membrane lipid composition of leaves of winter wheat seedlings in response to PEG-induced water stress. BMC Plant Biol 20: 84. http://dx.doi.org/10.1186/s12870-020-2257-1.

Weber S, Unker F, Friedt W. 2005. Improved doubled haploid production protocol for Brassica napus using microspore colchicine treatment in vitro and ploidy determination by flow cytometry. Plant Breed 124: 511-513.

Wedzony M, Foster BP, Zur I, et al. Progress in doubled haploid technology in higher plants. In Touraev A, Foster BP, Jain EM, eds. Advances in haploid production in higher plants. Springer Science + Business Media BV, 2009, pp. 1-33.

Weerakoon SR. 2011. Producing inter-specific hybrids between Brassica juncea (L.) Czern \& coss and B. oleracea (L.) to synthesize trigenomic (abc) Brassica. J Sci Univ Kelaniya Sri Lanka 6: 13-34.

Weerakoon SR, Si P, Zili W, Meng J, Yan G. 2009. Production and confirmation of hybrids through interspecific crossing between tetraploid B. juncea and diploid B. oleracea towards a hexaploid Brassica population. In: 16th Australian Research Assembly on Brassicas, Ballarat Victoria, pp. 1-7.

Wen J, Zhu L, Qi L, et al. 2012. Characterization of interploid hybrids from crosses between Brassica juncea and B. oleracea and the production of yellow-seeded B. napus. Theor Appl Genet 125(1): 19-32.

Xie X, Zhang X, He Q. 2013. Identification of drought resistance of rapeseed (Brassica napus L.) during germination stage under PEG stress. J Food Agric Environ 11(2): 751-756.

Yang Ch, Zhang X, Zou Ch, Cheng Y, Zheng P, Li G. 2007. Effects of drought simulated by PEG-6000 on germination and seedling growth of rapeseed (Brassica napus L.). Chinese J Oil Crop Sci 29(4): 425-430.

Yuan X, Fu M, Li G, Wang J, Wei S, Cheng D. 2015. Evaluation of drought resistance of DH line from hybrid of B. napus and $B$. juncea. Chinese J Oil Crop Sci 37: 62-71.

Zhambakin KZH, Shamekova MKH, Daurova AK, et al. 2017. Production of rapeseed (Brassica napus) interspecific hybrids with rape (Brassica campestris) and mustard (Brassica juncea). Rep Nat Acad Sci Repub Kazakhstan 5(315): 114-122.

Zhou Y, Scarth R. 1995. Microspore culture of hybrids between Brassica napus and B. campestris. Acta Bot Sinica 37: 848-855.

Zhou WJ, Tang GX, Hagberg P. 2002. Efficient production of doubled haploid plants by immediate colchicine treatment of isolated microspores in winter Brassica napus. Plant Growth Reg 37: 185-192.

Cite this article as: Daurova A, Daurov D, Volkov D, Zhapar K, Raimbek D, Shamekova M, Zhambakin K. 2020. Doubled haploids of interspecific hybrids between Brassica napus and Brassica rapa for canola production with valuable breeding traits. OCL $27: 45$. 